\title{
Relationship between Body Mass Index and T-Scores of Bone Mineral Density in the Hip and Spine Regions among Older Adults with Diabetes: A Retrospective Review
}

\author{
Abdulaziz F. Hariri ${ }^{1}$, ${ }^{1}$ Mohammad N. Almatrafi, ${ }^{1}$ Aws B. Zamka, ${ }^{1}$ Abdullah S. Babaker, ${ }^{1}$ \\ Tariq M. Fallatah, ${ }^{1}$ Omar H. Althouwaibi, ${ }^{2}$ and Amre S. Hamdi ${ }^{3}$ \\ ${ }^{1}$ Faculty of Medicine, King Abdulaziz University, Jeddah, Saudi Arabia \\ ${ }^{2}$ Faculty of Medicine, University of Jeddah, Jeddah, Saudi Arabia \\ ${ }^{3}$ Consultant and Assistant Professor of Orthopedic Surgery, Faculty of Medicine, King Abdulaziz University, Jeddah, \\ Saudi Arabia
}

Correspondence should be addressed to Abdulaziz F. Hariri; aziz.f.hariri@gmail.com

Received 25 January 2019; Accepted 3 April 2019; Published 22 April 2019

Academic Editor: Monica Nannipieri

Copyright (c) 2019 Abdulaziz F. Hariri et al. This is an open access article distributed under the Creative Commons Attribution License, which permits unrestricted use, distribution, and reproduction in any medium, provided the original work is properly cited.

\begin{abstract}
Diabetes mellitus (DM) cases are increasing worldwide, especially in Saudi Arabia. Previous studies suggested a positive relationship between body mass index (BMI) and bone mineral density (BMD) levels. Generally, patients with low BMI $\left(<18.5 \mathrm{~kg} / \mathrm{m}^{2}\right)$ have reduced BMD levels and, thus, low T-scores; hence, they are categorized as osteopenic or osteoporotic. In this study, we aimed to determine whether a relationship between BMI and BMD T-scores in the hip and spine regions of patients with diabetes exists. This retrospective record review investigated older adult patients with diabetes in King Abdulaziz University Hospital ( $n=198$; age 50-90 years) who underwent BMD scan between January 1,2016, and June 25, 2018, regardless of their sex but limited to type 2 DM. The height and weight of all subjects were recorded, and BMI was calculated and categorized. We used SPSS version 21 for data analysis; measures of central tendencies, Pearson's correlations, chi-square tests, and independent $t$-tests were employed. We found positive relationships between BMI and BMD T-scores in the hip and spine regions (right femoral neck: $R=+0.214, P \leq 0.002$; total right hip: $R=+0.912$, $P \leq 0.001$; left femoral neck: $R=+0.939, P \leq 0.001$; total left hip: $R=+0.885, P \leq 0.001$; and total lumbar region: $R=+0.607$, $P \leq 0.001)$. Low BMI $\left(<18.5 \mathrm{~kg} / \mathrm{m}^{2}\right)$ could be a risk factor for osteoporosis, whereas normal $/$ high BMI could be protective against osteoporosis among adults with diabetes.
\end{abstract}

\section{Introduction}

Diabetes mellitus (DM) cases are increasing worldwide. DM results from dysfunction in glucose metabolism and has different classifications depending on the pathophysiological cause: type $1 \mathrm{DM}$ (T1DM) is caused by insulin deprivation, and type $2 \mathrm{DM}$ (T2DM) is caused by insulin desensitization accompanied by insufficient insulin production [1]. A retrospective study in the United States of America (USA) published in 2015 reported an estimated DM prevalence of 12-14\% between 2011 and 2012. In Saudi Arabia, a community-based research showed a total prevalence of $23.7 \%$. Another recent local study showed that $\mathrm{T} 2 \mathrm{DM}$ alone had a prevalence of $17.7 \%$ in men and $16.4 \%$ in women [2-5].

A comparative study in the USA concluded that a directly proportional relationship between body mass index (BMI), which is calculated as weight in kilograms divided by height in meters squared $\left(\mathrm{kg} / \mathrm{m}^{2}\right)$ [6], and DM prevalence exists [7]. A recent study in older adults that was conducted to explore the relationship between BMI and T2DM showed that a high BMI is considered a risk factor for T2DM complications. A BMI $>25 \mathrm{~kg} / \mathrm{m}^{2}$ is considered a predisposing factor for T2DM, and those with a BMI $>30 \mathrm{~kg} / \mathrm{m}^{2}$ 
have a $100 \%$ risk of developing T2DM compared with those with normal BMI [8].

Moreover, several studies demonstrated the relationship between low BMI, low bone mineral density (BMD) levels, and the risk of osteoporotic fractures [9-11], and some studies found that increased BMI is associated with elevated $\mathrm{BMD}$ levels and a reduced risk of fractures due to osteoporosis [12-14].

The major complications of DM include heart attack, stroke, kidney failure, blindness, and lower limb amputation $[15,16]$. T1DM patients have reduced BMD levels and a high risk of fractures, which are attributable to the reduction of bone formation markers and increased bone resorption markers. In T2DM patients, despite their relatively higher BMD levels, their fracture risk is similar to that in T1DM patients [17-21].

Furthermore, osteoporosis is one of the most prevalent diseases in the older population [22] and is caused by decreased bone quality and BMD [23]. BMD levels may reflect the skeletal condition of the body and could predict the probability of osteoporotic fractures [24, 25]. The World Health Organization (WHO) provided the following classification based on $T$-scores, which represent the number of standard deviations below or above the average BMD: normal $(>-1.0)$, osteopenic $(-1.1$ to -2.5$)$, and osteoporotic $(\leq-2.5)$ [26]. The prevalence of osteoporosis in Saudi Arabia in both genders aged $>55$ years is $>30 \%$ [27, 28]. Osteoporosis along with osteopenia is responsible for fragility fractures, which contribute to the increasing morbidity and mortality rates. A previous study published in 2015 showed that the proximal femoral fracture incidence is 5.89 per 1000 individuals, and the estimated lifetime spending for fragility femoral fractures was 9.34 billion USD [29-31]. Moreover, 17 billion USD was the total healthcare cost of two million cases of fractures in the USA alone, and such cost is calculated to increase to 25 billion USD in 2025 because of an estimated 50\% increase in fracture incidence [32].

Further studies are needed to explore the relationship between BMI and BMD levels, especially among older diabetic patients. To our knowledge, no relevant studies were conducted in Saudi Arabia. Thus, in this study, we aimed to determine the relationship between BMI and the BMD Tscores in the hip and spine regions of older adult diabetic patients in King Abdulaziz University Hospital and to compare the BMD levels and the corresponding $T$-scores between the regions.

\section{Methods}

2.1. Ethical Approval. Ethical clearance was obtained from the Institutional Review Board (IRB) of King Abdulaziz University Hospital.

2.1.1. Study Design and Population. This is a retrospective record review of older adult diabetic patients (aged 5090 years), regardless of ethnicity, nationality, sex, or type of $\mathrm{DM}$, who underwent bone mineral densitometric scans via dual-energy X-ray absorptiometry (DEXA) between January
1, 2016, and June 25, 2018; those with comorbidities such as hyperthyroidism, rheumatoid arthritis, end-stage renal disease, chronic renal disease, diabetic nephropathy, and Addison's disease; those who had undergone vertebrae fixation; and those who were receiving glucocorticoids, antiepileptics, chemotherapy, androgen antagonists, aromatase inhibitors, or anticoagulants were excluded.

2.1.2. Data Collection and Availability. Our convenience sample was composed of 550 subjects. This study was conducted at the King Abdulaziz University Hospital in Jeddah City, Saudi Arabia. We used a data collection sheet for our primary data, which contained the following parts: (1) demographic data: age, sex, ethnicity, weight, height, BMI values, and nationality; (2) type of DM: type 1 or type 2; and (3) BMD scan data: BMD levels and their corresponding $T$-scores at the right hip (femoral neck and total hip), left hip (femoral neck and total hip), and lumbar vertebrae (L1-L2 and total lumbar region).

We obtained and filtered the data using the hospital system according to our inclusion and exclusion criteria. Data were kept confidential, sealed with a passcode, and are available from the corresponding author upon request.

2.1.3. Data Entry and Analysis. We used Microsoft Excel ${ }^{\circledR}$ for data entry and the Statistical Package for the Social Sciences version 21 (SPSS Inc., Chicago, IL, USA) for data analysis. Chi-square and independent $t$-tests, measures of central tendencies, and Pearson's correlations were employed, and all statistical test results were considered significant if the $P$ value was less than 0.05 ; regarding the Pearson's coefficient $(r)$ value, if the result was 0 , it is considered as no relationship, weak strength relationship if less than 0.2 , moderate strength relationship if between 0.2 and 0.4 , and strong strength relationship if more than 0.4 . The interpretation of the signs positive $(+)$ and negative (-) depends on the two variables' signs that are being studied; as if both were positive/negative, it would indicate a direct proportional relationship, but if either one was positive or negative, the other was the opposite, and it would indicate an inverse relationship.

2.1.4. DEXA and T-Scores. DEXA scan, which is a standard way of assessing BMD, could provide data on fracture risk and $T$-scores. According to the WHO, T-scores represent the number of standard deviations below or above the average BMD. Based on the T-scores, patients are classified as follows: normal (>-1.0), osteopenic $(-1.0$ to -2.5$)$, and osteoporotic $(\leq-2.5)[26,33]$. BMD was expressed in $\mathrm{g} / \mathrm{cm}^{2}$.

2.1.5. BMI Categories. Weight, height, and BMI were obtained on site and before DEXA scans. The patients were classified according to the WHO classification [34]: underweight $\left(<18.5 \mathrm{~kg} / \mathrm{m}^{2}\right)$, normal weight $\left(18.5-24.9 \mathrm{~kg} / \mathrm{m}^{2}\right)$, overweight $\left(25.0-29.9 \mathrm{~kg} / \mathrm{m}^{2}\right)$, obesity class I $(30.0-34.99 \mathrm{~kg} /$ $\left.\mathrm{m}^{2}\right)$, obesity class II $\left(35.0-39.99 \mathrm{~kg} / \mathrm{m}^{2}\right)$, and obesity class III $\left(>40.0 \mathrm{~kg} / \mathrm{m}^{2}\right)$. 


\section{Results}

Of the 550 files we have retrieved and after applying the inclusion and exclusion criteria, 198 patients were included in the analysis (women, 177 (88.50\%); men, 21 (11.50\%)). The demographic data are shown in Table 1 and Figure 1.

\subsection{Relationship between BMI and BMD T-Scores in the Hip} and Spine Regions. All relationships were strong positive significant relationships between BMI and BMD T-scores in the right total hip $(R=+0.912, P \leq 0.001)$, the left femoral neck $(R=+0.939, P \leq 0.001)$, total left hip $(R=+0.885$, $P \leq 0.001)$, and lumbar $1(R=+0.590, P \leq 0.001)$ and 2 vertebrae $(R=+0.587, P \leq 0.001)$; the total lumbar region $(R=+0.607, P \leq 0.001)$ was noted based on the Pearson's correlation expect for the right femoral neck which had a moderate positive relationship $(R=+0.214, \quad P \leq 0.002)$. Correlations between BMI and BMD $T$-scores are summarized in Table 2 and Figure 2.

3.2. Normative Comparison of BMI and BMD T-Scores in the Hip and Spine Regions according to Sex. The lowest means of BMD in both sexes were found in the left femoral neck (men, $0.766 \pm 0.1428$; women, $0.702 \pm 0.1355$ (both $P \leq 0.042$ ). The highest means of both BMD and T-scores in men were in the total lumbar region $(1.047 \pm 0.1794, \quad P \leq 0.001$ and $-0.367 \pm 1.6788, P \leq 0.001$, respectively). The lowest mean of $T$-scores in women was in the total lumbar region $(-1.460 \pm 1.3160, P \leq 0.001)$ (correlations between BMD levels, $T$-scores, and sex are summarized in Table 3 ).

\section{Discussion}

Our study's population, sample size, and demographic characteristics differ from other similar studies. For example, a previous study in China was conducted to identify the relationship between BMI and BMD; the study had two groups of postmenopausal women only (T2DM group and control group) [35]. Nevertheless, our sample is similar due to the great disparity in relation to the female to male ratio; that is, probably due to being a woman itself regardless of age, it is more associated with low BMD compared with men. Thus, DEXA scan for women is a priority according to the US Preventive Services Task Force, especially after menopause [36].

All correlations between BMI and BMD T-scores in the hip and spine regions were significantly directly proportional although the correlation strength varied between the strong and moderate, which means that an increase in BMI could result in increased BMD T-scores, and vice versa. Both the right femoral neck and total right hip had weak correlations. The correlations in all relationships were strong positive significant relationships (the right total hip, the left femoral neck, total left hip, lumbar 1 and 2 vertebrae, and total lumbar region in comparison to the right femoral neck which showed moderate positive relationship). Previous studies concluded that when BMI increases, BMD levels will also increase, which further supports our findings [37, 38].
TABLE 1: Demographic characteristics of the patients with type 2 diabetes mellitus.

\begin{tabular}{lc}
\hline Categories & T2DM subjects $(n=198)$ \\
\hline Age $($ years $)$ & $63.64 \pm 8.249$ \\
Height $(\mathrm{cm})$ & $154.42 \pm 8.04$ \\
Weight $(\mathrm{kg})$ & $76.14 \pm 14.23$ \\
BMI $\left(\mathrm{kg} / \mathrm{m}^{2}\right)$ & $31.96 \pm 5.57$ \\
BMI categories & 1 \\
$\quad$ Underweight $\left(<18.5 \mathrm{~kg} / \mathrm{m}^{2}\right)$ & 17 \\
$\quad$ Normal weight $\left(18.5-24.9 \mathrm{~kg} / \mathrm{m}^{2}\right)$ & 66 \\
Overweight $\left(25.0-29.9 \mathrm{~kg} / \mathrm{m}^{2}\right)$ & 62 \\
Obesity class I $\left(30.0-34.99 \mathrm{~kg} / \mathrm{m}^{2}\right)$ & 32 \\
Obesity class II $\left(35.0-39.99 \mathrm{~kg} / \mathrm{m}^{2}\right)$ & 20 \\
Obesity class III $\left(>40.0 \mathrm{~kg} / \mathrm{m}^{2}\right)$ & 100 \\
Nationality & 98 \\
Saudis & \\
Non-Saudis & 182 \\
Ethnicity & 16 \\
Arabs & \\
Non-Arabs & 21 \\
Sex & 177 \\
Male & \\
Female &
\end{tabular}

T2DM: type 2 diabetes mellitus. Values are presented as mean \pm SD.

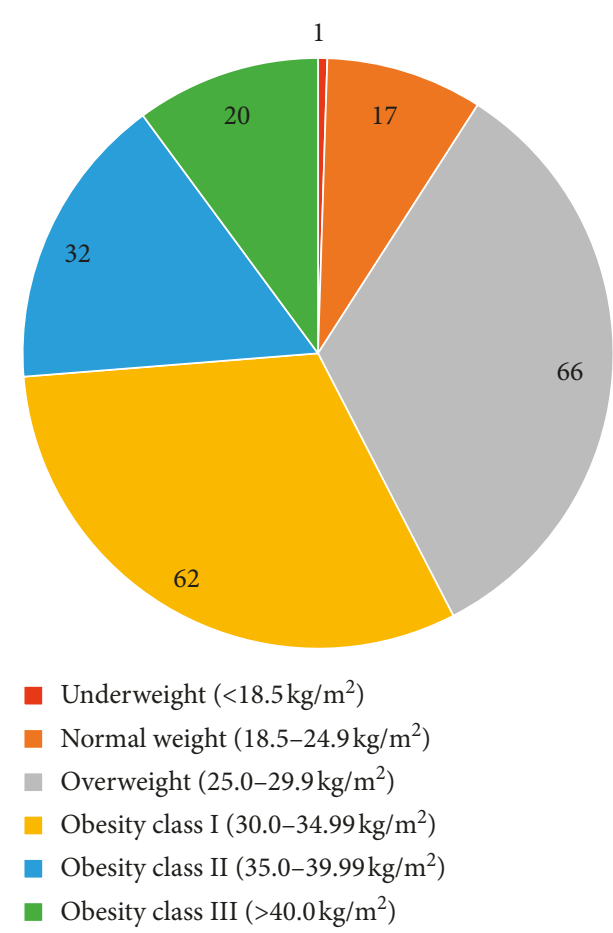

FIgURE 1: BMI categories of our sample.

Moreover, other studies explained that such relationship exists because heavy body weight could result in bone remodeling to compensate for the heavy mechanical load $[39,40]$. Another study suggested that an increased BMI could subsequently increase the levels of leptin, which contributes to the relationship by promoting osteoblast production and functions [41-44]. Other studies showed that early postmenopausal women with a low BMI have low 
TABLE 2: Relationship between BMI and BMD T-scores in the hip and spine regions.

\begin{tabular}{lcc}
\hline$T$-score regions & $R$ values & $P$ values \\
\hline Right femoral neck & +0.214 & $\leq 0.002$ \\
Total right hip region & +0.912 & $\leq 0.001$ \\
Left femoral neck & +0.939 & $\leq 0.001$ \\
Left total hip & +0.885 & $\leq 0.001$ \\
Lumbar 1 vertebra & +0.590 & $\leq 0.001$ \\
Lumbar 2 vertebra & +0.587 & $\leq 0.001$ \\
Total lumbar region & +0.607 & $\leq 0.001$ \\
\hline
\end{tabular}

$R$ : Pearson's correlation coefficients; $P$ : partial correlation coefficients.

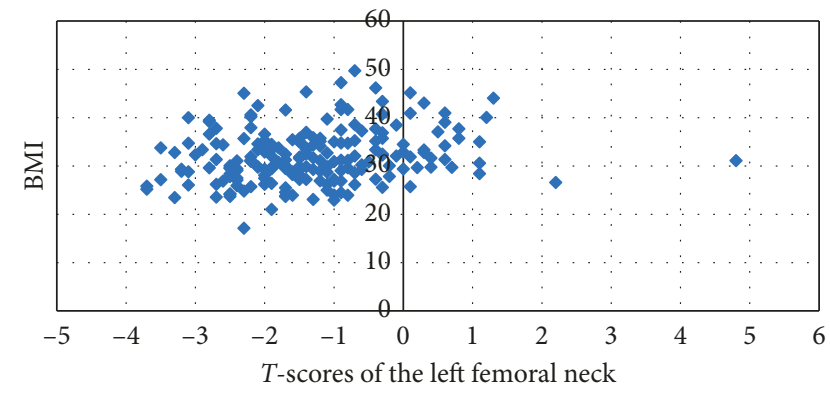

FIgURE 2: Correlation between BMI values and T-scores of the left femoral neck.

TABle 3: Pearson's correlations between BMD levels, T-scores, and sex.

\begin{tabular}{|c|c|c|c|}
\hline Bone parameters & Men $(n=21)$ & Women $(n=177)$ & $P$ values \\
\hline \multicolumn{4}{|l|}{ Right femoral neck } \\
\hline $\operatorname{BMD}\left(\mathrm{g} / \mathrm{cm}^{2}\right)$ & $0.784 \pm 0.1323$ & $0.7127 \pm 0.1422$ & $\leq 0.028$ \\
\hline$T$-score & $-1.029 \pm 0.1035$ & & $\leq 0.402$ \\
\hline \multicolumn{4}{|c|}{ Total right hip region } \\
\hline $\operatorname{BMD}\left(\mathrm{g} / \mathrm{cm}^{2}\right)$ & $0.921 \pm 0.1407$ & $0.8263 \pm 0.1524$ & $\leq 0.007$ \\
\hline$T$-score & $-0.714=$ & & $\leq 0.298$ \\
\hline \multicolumn{4}{|c|}{ Left femoral neck } \\
\hline $\operatorname{BMD}\left(\mathrm{g} / \mathrm{cm}^{2}\right)$ & $0.766 \pm 0.1428$ & $0.702 \pm 0.1355$ & $\leq 0.042$ \\
\hline$T$-score & $-1.167 \pm$ & -1.35 & $\leq 0.510$ \\
\hline \multicolumn{4}{|c|}{ Total left hip region } \\
\hline $\operatorname{BMD}\left(\mathrm{g} / \mathrm{cm}^{2}\right)$ & $0.911 \pm 0.1511$ & $0.819 \pm 0.1443$ & $\leq 0.007$ \\
\hline$T$-score & $-0.762 \pm 1.0447$ & & $\leq 0.278$ \\
\hline \multicolumn{4}{|c|}{ Lumbar 1 vertebra } \\
\hline $\operatorname{BMD}\left(\mathrm{g} / \mathrm{cm}^{2}\right)$ & $0.983 \pm 0.1717$ & & $\leq 0.001$ \\
\hline T-score & $-0.668 \pm 1.5981$ & & $\leq 0.078$ \\
\hline \multicolumn{4}{|c|}{ Lumbar 2 vertebra } \\
\hline $\operatorname{BMD}\left(\mathrm{g} / \mathrm{cm}^{2}\right)$ & $1.037 \pm 0.2041$ & & $\leq 0.001$ \\
\hline$T$-score & $-0.481 \pm 1.886$ & $-1.302 \pm 1.4101$ & $\leq 0.016$ \\
\hline \multicolumn{4}{|c|}{ Total lumbar region } \\
\hline $\operatorname{BMD}\left(\mathrm{g} / \mathrm{cm}^{2}\right)^{\circ}$ & $1.047 \pm 0.1794$ & $0.8911 \pm 0.1482$ & $\leq 0.001$ \\
\hline$T$-score & $-0.367 \pm 1.6788$ & $-1.460 \pm 1.3160$ & $\leq 0.001$ \\
\hline
\end{tabular}

Values are presented as mean \pm SD.

BMD compared with women with a higher BMI, further supporting the positive relationship between the two variables $[13,45]$.

Majority of our subjects are classified as overweight and obesity class I and II (mean BMI $=31.96 \mathrm{~kg} / \mathrm{m}^{2}$ ), possibly because some of the patients are on insulin therapy (insulin is an anabolic hormone that could increase weight) and because of the sedentary lifestyle and unhealthy dietary choices of patients.

Comparing between both sexes' means of $T$-scores in the hip and spine regions, the lowest mean of $T$-scores in men was in the left femoral neck, and the lowest and highest means of $T$-scores in women and men, respectively, were in the total lumbar region. The highest mean of $T$-scores in women was in the total right hip region. According to the WHO, an increase in $T$-score indicates a worsening bone condition (i.e., the more negative the score is, the worse the category is) [26].

Recent similar studies published in 2012, 2016, and 2018 in the USA, China, and India, respectively, compared the means of BMD and $T$-scores, but their studied population differed. For instance, the study in the USA involved only women who were subcategorized according to their insulin dependency, and the study in China and that in India included both sexes, but neither of them was diabetic; moreover, the age range in the study in India was different from that in our study.

We noticed that the means of BMD T-scores in the regions of interest in our study were worse than those in previous studies [46-48], probably because all our subjects are diagnosed with type 2 diabetes, and DM, as demonstrated in previous studies, is a contributing factor to such difference because of its effect at the cellular level. Prolonged hyperglycemia is found to affect both the function and quantity of osteoblasts by disrupting the response to vitamin $\mathrm{D}$ and stimulating glycation of multiple proteins. Glycation produces end products that could accumulate and be embedded into the bony matrix and consequently damage the bones [16, 49-54]. Moreover, another possible reason could be the duration of DM and menopause. However, in our study, relevant data were missing in the records, thereby raising the probability of confounders. In addition, the differences in nationalities, ethnicities, and genetic makeup may also play a role. Thus, we could hypothesize that, generally, Saudis and/or Arabs may have lower BMD levels than Americans, Chinese, or Indians; however, this should be further explored in future identical comparative study.

This study has some unavoidable limitations, especially with its retrospective nature. First, the number of female subjects in this study is significantly greater than that of male subjects, which could be because the female sex is considered a risk factor for low BMD at any age and especially after menopause [36]. Second, this study focused on T2DM as a whole, and we did exclude those who were diagnosed with T1DM because of a significant numerical disparity between T1DM and T2DM patients in the data we retrieved and to assess and focus more on T2DM in specific. Third, we could not determine how long the subjects have been diagnosed as having DM as well as the duration of menopause. Fourth, not all lumbar region vertebrae were scanned; we found that scan data for L3 and L4 are missing in some patients. This could be because not all patients received the same treatment and a portion of patients had missing vertebrae congenitally. Hence, we excluded L3 and L4 to avoid missing data bias. 


\section{Conclusions}

Diabetic patients with high BMI possibly have a lower risk of osteoporosis than those with low BMI. All patients with diabetes should be encouraged and educated about controlling their diabetes and maintaining normal BMI or increasing BMI for those with low BMD by having wellbalanced and healthy diets to prevent the risk of fragility fractures and osteoporosis.

Finally, a local BMD screening program for older adults with DM is highly encouraged for early detection of osteoporotic risk and to prevent further complications. Future studies with a larger sample size are warranted to further explore the relationship between BMI and BMD Tscores of people with diabetes and the pathophysiological mechanisms.

\section{Conflicts of Interest}

The authors declare that there are no conflicts of interest regarding the publication of this paper.

\section{References}

[1] American Diabetes Association, "Diagnosis and classification of diabetes mellitus," Diabetes Care, vol. 37, no. 1, pp. S81-S90, 2014.

[2] International Diabetes Federation, IDF Diabetes Atlas, International Diabetes Federation, Brussels, Belgium, 6th edition, 2013, http://www.diabetesatlas.org.

[3] A. Menke, S. Casagrande, L. Geiss, and C. C. Cowie, "Prevalence of and trends in diabetes among adults in the United States, 1988-2012," Journal of the American Medical Association, vol. 314, no. 10, pp. 1021-1029, 2015.

[4] M. M. Al-Nozha, M. A. Al-Maatouq, Y. Y. Al-Mazrou et al., "Diabetes mellitus in Saudi Arabia," Saudi Medical Journal, vol. 25, no. 11, pp. 1603-1610, 2004.

[5] S. M. Bahijri, H. A. Jambi, R. M. Al Raddadi, G. Ferns, and J. Tuomilehto, "The prevalence of diabetes and prediabetes in the adult population of Jeddah, Saudi Arabia-a communitybased survey," PLoS One, vol. 11, no. 4, Article ID e0152559, 2016.

[6] G. A. Bray, "Clinical evaluation of the obese patient," Best Practice \& Research Clinical Endocrinology \& Metabolism, vol. 13, no. 1, pp. 71-92, 1999.

[7] H. E. Bays, R. H. Chapman, S. Grandy, and SHIELD Investigators' Group, “The relationship of body mass index to diabetes mellitus, hypertension and dyslipidaemia: comparison of data from two national surveys," International Journal of Clinical Practice, vol. 61, no. 5, pp. 737-747, 2007.

[8] N. Gray, G. Picone, F. Sloan, and A. Yashkin, "The relationship between BMI and onset of diabetes mellitus and its complications among US older adults," Southern Medical Journal, vol. 108, no. 1, pp. 29-36, 2015.

[9] R. M. Joakimsen, V. Fønnebø, J. H. Magnus, A. Tollan, and A. Johanne Søgaard, "The tromsø study: body height, body mass index and fractures," Osteoporosis International, vol. 8, no. 5, pp. 436-442, 1998.

[10] D. K. Roy, T. W. O’Neill, J. D. Finn et al., "Determinants of incident vertebral fracture in men and women: results from the European Prospective Osteoporosis Study (EPOS)," Osteoporosis International, vol. 14, no. 1, pp. 19-26, 2003.
[11] C. De Laet, J. A. Kanis, A. Odén et al., "Body mass index as a predictor of fracture risk: a meta-analysis," Osteoporosis International, vol. 16, no. 11, pp. 1330-1338, 2005.

[12] D. T. Felson, Y. Zhang, M. T. Hannan, and J. J. Anderson, "Effects of weight and body mass index on bone mineral density in men and women: the Framingham study," Journal of Bone and Mineral Research, vol. 8, pp. 567-573, 1993.

[13] P. Ravn, G. Cizza, N. H. Bjarnason et al., "Low body mass index is an important risk factor for low bone mass and increased bone loss in early postmenopausal women," Journal of Bone and Mineral Research, vol. 14, no. 9, pp. 1622-1627, 1999.

[14] I. R. Reid, R. Ames, M. C. Evans et al., "Determinants of total body and regional bone mineral density in normal postmenopausal women-a key role for fat mass," Journal of Clinical Endocrinology \& Metabolism, vol. 75, no. 1, pp. 45-51, 1992.

[15] P. A. Lazzarini, J. M. Gurr, J. R. Rogers, A. Schox, and S. M. Bergin, "Diabetes foot disease: the Cinderella of Australian diabetes management?," Journal of Foot and Ankle Research, vol. 5, no. 1, p. 24, 2012.

[16] P. Vestergaard, "Discrepancies in bone mineral density and fracture risk in patients with type 1 and type 2 diabetes-a meta-analysis," Osteoporosis International, vol. 18, no. 4, pp. 427-444, 2007.

[17] I. D. Baker, Diabetes: The Silent Pandemic and Its Impact on Australia, Baker IDI, Melbourne, Australia, 2012.

[18] M. Janghorbani, D. Feskanich, W. C. Willett, and F. Hu, "Prospective study of diabetes and risk of hip fracture: the nurses' health study," Diabetes Care, vol. 29, no. 7, pp. 1573-1578, 2006.

[19] M. Pedrazzoni, G. Ciotti, G. Pioli et al., "Osteocalcin levels in diabetic subjects," Calcified Tissue International, vol. 45, no. 6, pp. 331-336, 1989.

[20] J. M. Olmos, J. L. Pérez-Castrillón, M. T. García, J. C. Garrido, J. A. Amado, and J. González-Macías, "Bone densitometry and biochemical bone remodeling markers in type 1 diabetes mellitus," Bone and Mineral, vol. 26, no. 1, pp. 1-8, 1994.

[21] P. L. Selby, P. A. Shearing, and S. M. Marshall, "Hydroxyproline excretion is increased in diabetes mellitus and related to the presence of microalbuminuria," Diabetic Medicine, vol. 12, no. 3, pp. 240-243, 1995.

[22] A. Arabi, M. Nabulsi, J. Maalouf et al., "Bone mineral density by age, gender, pubertal stages, and socioeconomic status in healthy Lebanese children and adolescents," Bone, vol. 35, no. 5, pp. 1169-1179, 2004.

[23] M. S. Nanes and C. B. Kallen, "Osteoporosis," Seminars in Nuclear Medicine, vol. 44, no. 6, pp. 439-450, 2014.

[24] A. C. Looker, L. J. Melton, T. Harris, L. Borrud, J. Shepherd, and J. McGowan, "Age, gender, and race/ethnic differences in total body and subregional bone density," Osteoporosis International, vol. 20, no. 7, pp. 1141-1149, 2009.

[25] Q. Wu, J. J. Lefante, J. C. Rice, and J. H. Magnus, “Age, race, weight, and gender impact normative values of bone mineral density," Gender Medicine, vol. 8, no. 3, pp. 189-201, 2011.

[26] J. A. Kanis and J. A. Kanis, "Assessment of fracture risk and its application to screening for postmenopausal osteoporosis: synopsis of a WHO report," Osteoporosis International, vol. 4, no. 6, pp. 368-381, 1994.

[27] M. Sadat-Ali, I. M. Al-Habdan, H. A. Al-Turki, and M. Q. Azam, "An epidemiological analysis of the incidence of osteoporosis and osteoporosis-related fractures among the Saudi Arabian population," Annals of Saudi Medicine, vol. 32, no. 6, pp. 637-641, 2012. 
[28] M. I. El-Desouki and R. A. Sulimani, "High prevalence of osteoporosis in Saudi men," Saudi Medical Journal, vol. 28, no. 5, pp. 774-777, 2007.

[29] M. Mariconda, G. G. Costa, S. Cerbasi et al., "The determinants of mortality and morbidity during the year following fracture of the hip: a prospective study," Bone \& Joint Journal, vol. 97-B, no. 3, pp. 383-390, 2015.

[30] A. S. Nazrun, M. N. Tzar, S. A. Mokhtar, and I. N. Mohamed, "A systematic review of the outcomes of osteoporotic fracture patients after hospital discharge: morbidity, subsequent fractures, and mortality," Therapeutics and Clinical Risk Management, vol. 10, pp. 937-948, 2014.

[31] M. Sadat-Ali, D. A. Al-Dakheel, M. Q. Azam et al., "Reassessment of osteoporosis-related femoral fractures and economic burden in Saudi Arabia," Archives of Osteoporosis, vol. 10, no. 1, p. 37, 2015.

[32] R. Burge, B. Dawson-Hughes, D. H. Solomon, J. B. Wong, A. King, and A. Tosteson, "Incidence and economic burden of osteoporosis-related fractures in the United States, 20052025," Journal of Bone and Mineral Research, vol. 22, no. 3, pp. 465-475, 2007.

[33] G. M. Blake and I. Fogelman, "The role of DXA bone density scans in the diagnosis and treatment of osteoporosis," Postgraduate Medical Journal, vol. 83, no. 982, pp. 509-517, 2007.

[34] World Health Organization, Obesity: Preventing and Managing the Global Epidemic, World Health Organization, Geneva, Switzerland, 2000.

[35] P.-F. Shan, X.-P. Wu, H. Zhang et al., "Bone mineral density and its relationship with body mass index in postmenopausal women with type 2 diabetes mellitus in mainland China," Journal of Bone and Mineral Metabolism, vol. 27, no. 2, pp. 190-197, 2009.

[36] S. J. Curry, A. H. Krist, D. K. Owens et al., "Screening for osteoporosis to prevent fractures: US preventive services task force recommendation statement," Journal of the American Medical Association, vol. 319, no. 24, pp. 2521-2531, 2018.

[37] S. Kirchengast, B. Peterson, G. Hauser, and W. Knogler, "Significance of body weight status for bone density in the elderly and very old," Zeitschrift für Gerontologie und Geriatrie, vol. 34, no. 4, pp. 313-318, 2001.

[38] A. Doğan, G. F. Nakipoğlu-Yüzer, M. T. Yıldızgören, and N. Özgirgin, "Is age or the body mass index (BMI) more determinant of the bone mineral density (BMD) in geriatric women and men?," Archives of Gerontology and Geriatrics, vol. 51, no. 3, pp. 338-341, 2010.

[39] D. Kang, Z. Liu, Y. Wang et al., "Relationship of body composition with bone mineral density in northern Chinese men by body mass index levels," Journal of Endocrinological Investigation, vol. 37, no. 4, pp. 359-367, 2014.

[40] J. Wee, B. Y. Sng, L. Shen, C. T. Lim, G. Singh, and S. D. De, "The relationship between body mass index and physical activity levels in relation to bone mineral density in premenopausal and postmenopausal women," Archives of Osteoporosis, vol. 8, no. 1-2, p. 162, 2013.

[41] M. Russell, N. Mendes, K. K. Miller et al., "Visceral fat is a negative predictor of bone density measures in obese adolescent girls," Journal of Clinical Endocrinology \& Metabolism, vol. 95, no. 3, pp. 1247-1255, 2010.

[42] M. W. Hamrick, M. A. Della-Fera, Y.-H. Choi, C. Pennington, D. Hartzell, and C. A. Baile, "Leptin treatment induces loss of bone marrow adipocytes and increases bone formation in leptin-deficient ob/ob mice," Journal of Bone and Mineral Research, vol. 20, no. 6, pp. 994-1001, 2005.
[43] C. M. Steppan, D. T. Crawford, K. L. Chidsey-Frink, H. Ke, and A. G. Swick, "Leptin is a potent stimulator of bone growth in ob/ob mice," Regulatory Peptides, vol. 92, no. 1-3, pp. 73-78, 2000.

[44] J. O. Gordeladze, C. A. Drevon, U. Syversen, and J. E. Reseland, "Leptin stimulates human osteoblastic cell proliferation, de novo collagen synthesis, and mineralization: impact on differentiation markers, apoptosis, and osteoclastic signaling," Journal of Cellular Biochemistry, vol. 85, no. 4, pp. 825-836, 2002.

[45] N. H. Bjarnason and C. Christiansen, "The influence of thinness and smoking on bone loss and response to hormone replacement therapy in early postmenopausal women," Journal of Clinical Endocrinology \& Metabolism, vol. 85, no. 2, pp. 590-596, 2000.

[46] R. Garg, Z. Chen, T. Beck et al., "Hip geometry in diabetic women: implications for fracture risk," Metabolism, vol. 61, no. 12, pp. 1756-1762, 2012.

[47] Y. C. Lu, Y. C. Lin, Y. K. Lin et al., "Prevalence of osteoporosis and low bone mass in older Chinese population based on bone mineral density at multiple skeletal sites," Scientific Reports, vol. 6, no. 1, article 25206, 2016.

[48] N. S. Kadam, S. A. Chiplonkar, A. V. Khadilkar, and V. V. Khadilkar, "Prevalence of osteoporosis in apparently healthy adults above 40 years of age in Pune city, India," Indian Journal of Endocrinology and Metabolism, vol. 22, no. 1, pp. 67-73, 2018.

[49] M. Ghodsi, A. A. Keshtkar, E. Nasli-Esfahani, S. Alatab, and M. R. Mohajeri-Tehrani, "Mechanisms involved in altered bone metabolism in diabetes: a narrative review," Journal of Diabetes \& Metabolic Disorders, vol. 15, no. 1, p. 52, 2016.

[50] V. Sundararaghavan, M. M. Mazur, B. Evans, J. Liu, and N. A. Ebraheim, "Diabetes and bone health: latest evidence and clinical implications," Therapeutic Advances in Musculoskeletal Disease, vol. 9, no. 3, pp. 67-74, 2017.

[51] C. Hamann, S. Kirschner, K.-P. Günther, and L. C. Hofbauer, "Bone, sweet bone-osteoporotic fractures in diabetes mellitus," Nature Reviews Endocrinology, vol. 8, no. 5, pp. 297305, 2012.

[52] P. Srikanthan, C. J. Crandall, D. Miller-Martinez et al., "Insulin resistance and bone strength: findings from the study of midlife in the United States," Journal of Bone and Mineral Research, vol. 29, no. 4, pp. 796-803, 2014.

[53] W. Yan and X. Li, "Impact of diabetes and its treatments on skeletal diseases," Frontiers of Medicine, vol. 7, no. 1, pp. 81-90, 2013.

[54] S. Adami, "Bone health in diabetes: considerations for clinical management," Current Medical Research and Opinion, vol. 25, no. 5, pp. 1057-1072, 2009. 


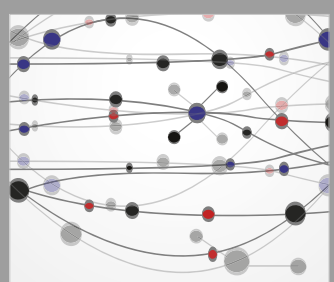

The Scientific World Journal
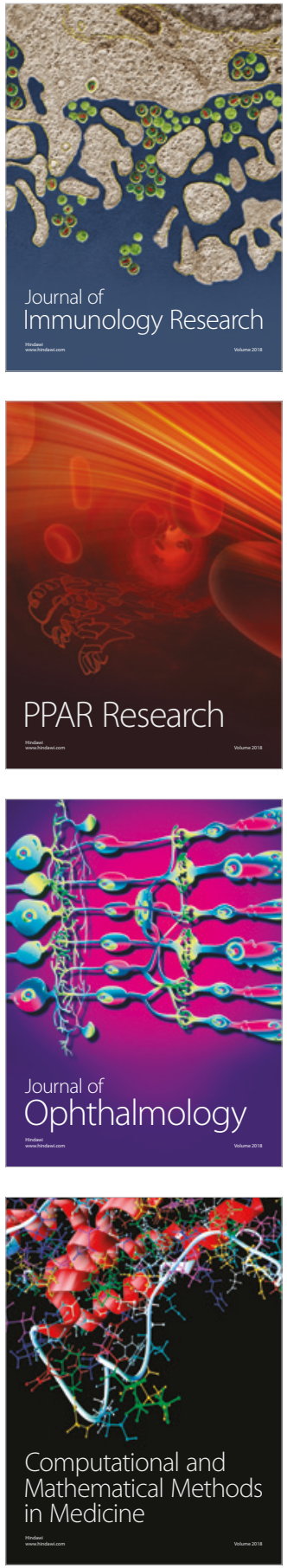

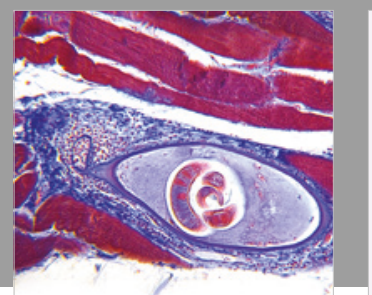

Gastroenterology Research and Practice

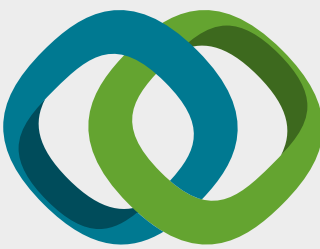

\section{Hindawi}

Submit your manuscripts at

www.hindawi.com
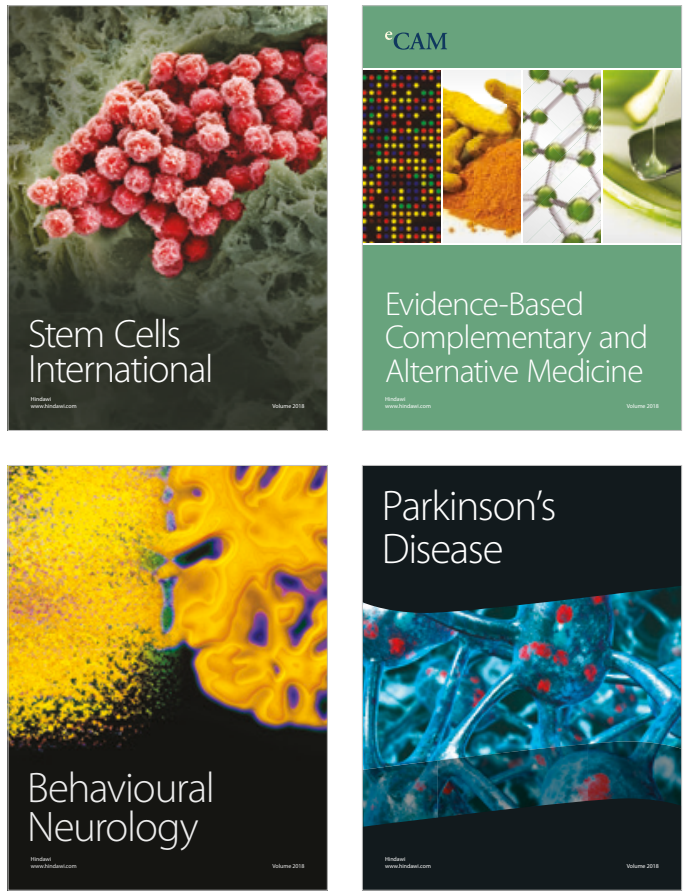

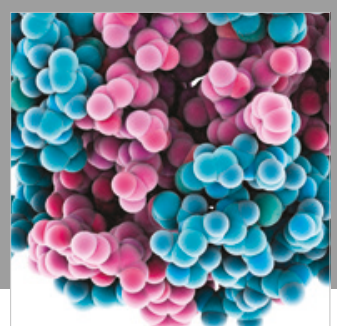

ournal of

Diabetes Research

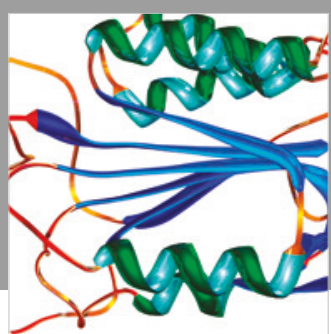

Disease Markers
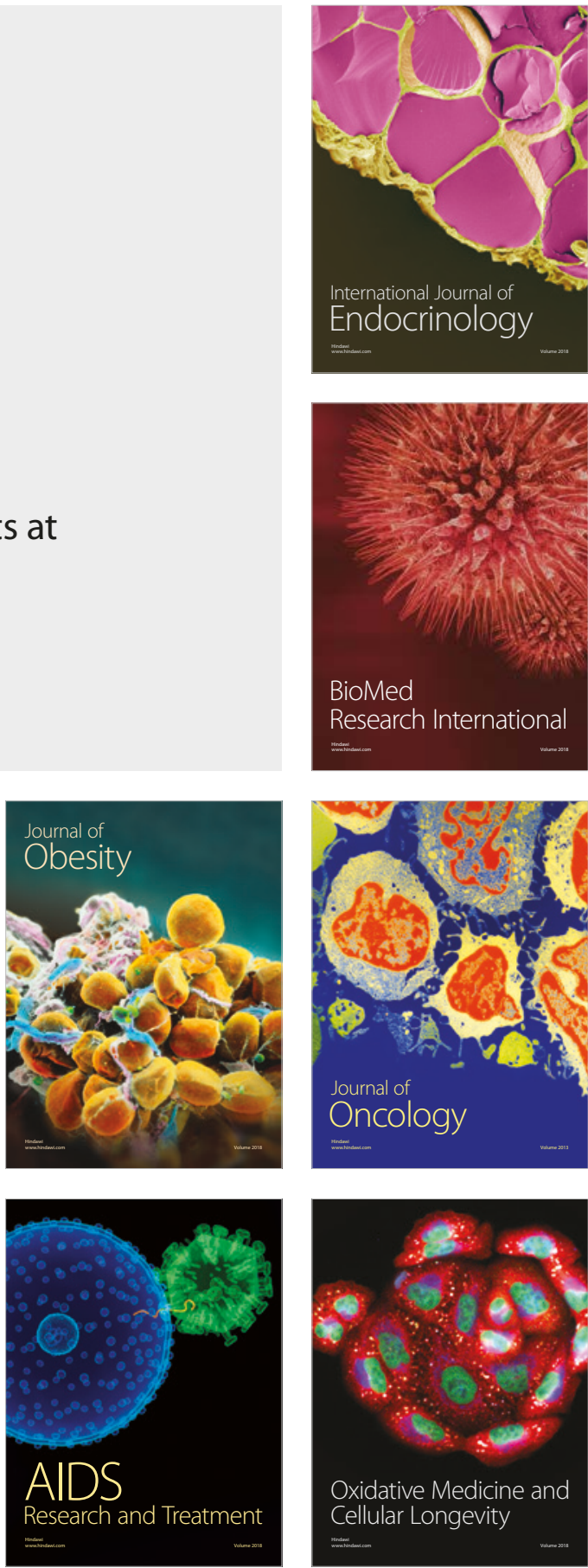